\title{
LA LUCHA ANTITERRORISTA Y EL NUEVO SISTEMA DE SEGURIDAD INTERNACIONAL TRAS EL 11 DE SEPTIEMBRE: ¿UNA CONSECUENCIA LÓGICA?
}

Aleksandro Palomo Garrido

EL 11 DE SEPTIEMbre de 2001 marcó un punto de inflexión en el sistema de seguridad internacional. Su trascendencia viene, no tanto por las consecuencias del ataque en sí, sino por las decisiones adoptadas por el gobierno estadounidense con posterioridad al ataque. Estas decisiones, agrupadas bajo la bandera de la lucha contra el terrorismo, se han mostrado con frecuencia como la consecuencia lógica a los hechos producidos ese 11 de septiembre (11-S). Sin embargo, en el ámbito científico no podemos admitir este determinismo mecánico. El abanico de decisiones por las que podía optar el gobierno estadounidense tras el 11-S era amplio y diverso. En concreto, el gobierno de Bush escogió la lucha contra el terrorismo como respuesta a estos acontecimientos. A lo largo del texto, trataremos de responder a las motivaciones que empujaron al gobierno de Bush a emprender la ruta de la lucha contra el terrorismo y las consecuencias que esta decisión ha tenido sobre el sistema de seguridad internacional.

En primer lugar, dataremos el comienzo de la lucha antiterrorista. Como veremos más adelante, las medidas de emergencia antiterroristas se comenzaron a aplicar con anterioridad a los atentados del 11-S. Por tanto, la causalidad establecida habitualmente entre el 11-S y el comienzo de la lucha antiterrorista no es exacta. Esta imprecisión da pie a buscar otras posibles causas que motivaron el comienzo de la lucha antiterrorista y que se intentarán definir a lo 
largo del texto. A continuación, revisaremos los cambios que se produjeron en la agenda de seguridad global posteriormente al 11-S. En concreto, el terrorismo pasó a ser el primer objetivo en la agenda de seguridad de la onU.

También, analizaremos las repercusiones que tuvo la decisión del gobierno estadounidense de sacar adelante su nueva política de seguridad, basada en las intervenciones militares preventivas, ya fuera con el respaldo de la comunidad internacional o en solitario. Este unilateralismo de Estados Unidos desfiguró por completo el sistema de seguridad internacional basado en el consenso. Desbarató todos los avances en la dirección de expandir un sistema legal de seguridad basado en la autoridad de la onU. El nuevo sistema de seguridad que surgió suponía un regreso al tradicional sistema de alianzas militares. Además, como veremos más adelante, la agresiva política exterior estadounidense provocó desconfianzas entre la mayoría de los gobiernos. Esta desconfianza alentó una escalada armamentística como no se veía desde la Guerra Fría.

Este panorama internacional nos lleva a la conclusión de que el nuevo sistema de seguridad surgido tras el 11-S no garantizaba con éxito el orden internacional, sino más bien todo lo contrario. Esta observación nos llevará a preguntar por qué el gobierno de Estados Unidos decidió emprender esta nueva senda arrastrando consigo a todo el sistema internacional. Dividiremos las posibles razones en explicaciones con motivaciones políticas y motivaciones económicas. Con ello pretendemos alcanzar una explicación racional que logre argumentar satisfactoriamente el porqué de las decisiones del gobierno de Washington.

La intención de razonar estas decisiones consiste en esclarecer las motivaciones que las respaldaron y destruir un axioma establecido en la mayoría de las investigaciones sobre seguridad internacional posteriores al 11-S. Este axioma consiste en la aceptación sin cuestionamiento posible de que las decisiones tomadas por el gobierno de Estados Unidos a raíz del 11-S eran las únicas posibles y las más convenientes. Por motivos de extensión, este texto no puede abordar el planteamiento de las alternativas a las decisiones que adoptó el gobierno de Bush. Eso lo dejaremos para futuras investigaciones. Lo que sí se pretende esclarecer es que las decisiones 
adoptadas en Washington no fueron las mejores para garantizar el orden internacional y que existen motivaciones detrás de tales decisiones que no siempre tienen que ver con el objetivo de combatir el terrorismo.

\section{Conceptos bÁsicos}

No se intenta aquí plantear un debate sobre el concepto de la seguridad internacional. Por tanto, partimos del concepto tradicional de seguridad internacional por motivos prácticos. ${ }^{1}$ Sin embargo, se ha tenido en cuenta el debate académico actual que está replanteando dicho concepto y que busca añadir nuevos factores de seguridad además del militar. ${ }^{2}$ Otro concepto a tener en cuenta es el del sistema internacional. Definiremos el sistema internacional de acuerdo con la teoría del sistema-mundo. ${ }^{3}$ Se considerará al sistema internacional como el conjunto de relaciones entre los principales actores que son los Estados, las corporaciones transnacionales y las organizaciones no gubernamentales (ONG). También consideraremos a los organismos intergubernamentales (OIG) como un actor semiindependiente, ya que depende fundamentalmente de los Estados. ${ }^{4}$ La estructura básica del sistema se construye en torno a un centro hegemónico que está formado por Estados Unidos y sus principales aliados, la Unión Europea y Japón.

Podemos considerar al sistema nacido en 1989 como un sistema nuevo y diferenciado de su predecesor, el sistema de la Guerra Fría, por la variación en los factores, que han contribuido a aumentar el número de actores, y porque las relaciones entre los actores

${ }^{1}$ Ersel Aydinli y James N. Rosenau, Globalization, Security, and the Nation State, Albany, SUNY Press, 2012.

${ }^{2}$ Barry Buzan et al., Security: A New Framework for Analysis, Boulder, Lynny Rienner Publishers, 1998, p. 170.

${ }^{3}$ Immanuel Wallerstein, Capitalismo histórico y movimientos antisistémicos, Madrid, Akal, 2004; Giovanni Arrighi, Adam Smith en Pekin, Madrid, Akal, 2007.

${ }^{4}$ Aleksandro Palomo, "Apuntes teóricos para el estudio de la Globalización desde la perspectiva de las Relaciones Internacionales", en CONfines de Relaciones Internacionales y Ciencia Política, vol. 8, núm. 16, Tecnológico de Monterrey, 2012. 
obedecen a nuevas reglas. ${ }^{5}$ En primer lugar, el nuevo sistema ha adquirido, por primera vez en la Historia, dimensiones globales. Precisamente, el último concepto que precisa aclaración es el de la Globalización. Desde el punto de vista de este texto hablamos de la Globalización para referirnos al periodo histórico que sucede al de la Guerra Fría. Podemos tomar como referencia simbólica la caída del muro de Berlín en 1989. El desarrollo de las comunicaciones ha permitido desbaratar las compartimentaciones geográficas y temporales, y establecer unos lazos intercontinentales entre los actores del sistema. La interdependencia entre ellos, generada por la extensión e intensificación de las relaciones, es creciente y tienen consecuencias de orden político, económico y cultural.

\section{El comienzo de LA LUCHA ANTITERrorista}

Si bien normalmente se identifica a la fecha del 11 de septiembre en 2001 como la fecha de inicio de la lucha antiterrorista, la verdad es que algunos gobiernos del centro del sistema comenzaron a aplicar estas medidas un poco antes de esa fecha. La ley antiterrorista británica $^{6}$, una legislación represiva sin precedentes, se aprobó en el año 2000 y conoció desarrollos similares en otros Estados europeos. ${ }^{7}$ En Estados Unidos, ya en 1997, buena parte de los integrantes del futuro gobierno de G. W. Bush habían publicado un documento titulado "Proyecto para el nuevo siglo estadounidense". En este documento se instaba al gobierno a asegurar un nuevo periodo de hegemonía para Estados Unidos en el siglo xxi mediante una reorganización estratégica en la que la lucha contra el terrorismo era un eje fundamental. Los posteriores sucesos del 11-S facilitaron al gobierno de Bush la aplicación de dicha doctrina. ${ }^{8}$

${ }^{5}$ John Baylis y Steven Smith, The Globalization of World Politics, Nueva York, Oxford University Press, 2005.

${ }^{6}$ British Antiterrorist Act, http://www.legislation.gov.uk/ukpga/2001/24/ contents $(4 / 6 / 15)$.

${ }^{7}$ Robert Biel, El nuevo imperialismo, México, Siglo XXI, 2007, p. 518.

${ }^{8}$ Biel, op. cit., p. 519. 
El ordenamiento del sistema internacional se vio profundamente afectado por los atentados terroristas del 11-S, pero más por los cambios que dichos atentados provocaron en la política de Estados Unidos que por su trascendencia a nivel global. La potencia norteamericana quedó conmocionada al comprender, de repente, su vulnerabilidad. Tras los sucesos del 11-S, el gobierno de Estados Unidos se vio impelido a actuar de manera que no se pusiera en tela de juicio su capacidad de mantener el orden y la seguridad. Se puso en marcha la llamada lucha antiterrorista, que pretendía ser una respuesta frente a la agresión sufrida y restaurar el orden a nivel mundial.

En el interior de Estados Unidos se implementaron numerosas medidas de seguridad y leyes que enfatizaban la seguridad, aunque fuera en detrimento de las libertades civiles. ${ }^{9}$ La principal de estas leyes, la ley "Patriot" (2001), ${ }^{10}$ violaba cinco de las diez enmiendas de la Constitución: la libertad de expresión y reunión, la protección frente a registro y detenciones arbitrarias, el respeto de las garantías legales, el derecho a juicio público y la protección frente a castigos crueles e inusuales. ${ }^{11}$ Además, la definición que establecía de actividades terroristas era suficientemente ambigua y amplia como para catalogar de terrorismo a casi cualquier actividad criminal. ${ }^{12}$

En virtud de la seguridad nacional, se autorizaron las detenciones indefinidas contra los "sospechosos" de actividades que pudieran poner en riesgo dicha seguridad. ${ }^{13}$ Además, se aprobaron decretos en los que se establecían tribunales militares para juzgar a extranjeros sin posibilidad de que éstos pudieran recurrir su sentencia ante la justicia civil. También se expandieron los poderes de

${ }^{9}$ Noam Chomsky, Estados fallidos, Barcelona, Público, 2010.

${ }^{10}$ http:/ / www.justice.gov/archive/ll/highlights.htm (3/6/15)

11 Marco A. Gandásegui y Dídimo Castillo (coord.), Estados Unidos: la crisis sistémica y las nuevas condiciones de legitimación, México, Siglo XXI, 2010, p. 372.

12 La definición oficial que hace Estados Unidos del concepto terrorismo es: "la violencia perpetrada contra civiles inocentes por grupos privados clandestinos con la intención de alcanzar sus propios objetivos políticos”. Zbigniew Brzezinski, El dilema de EEUU: ¿Dominación global o liderazgo global?, Barcelona, Paidós, 2005, p. 241.

${ }^{13}$ Chomsky, op. cit. 
vigilancia del gobierno reduciendo los criterios mínimos exigibles para su autorización y limitando la competencia de los tribunales a la hora de autorizar el espionaje. La ley "Homeland Security" (2002) permitía al Departamento de Seguridad Nacional recabar todo tipo de información sobre los ciudadanos, incluso accediendo a los correos electrónicos personales. ${ }^{14}$ Todas estas nuevas leyes fueron aprobadas sin apenas debate público, ni siquiera en el Congreso. A pesar de que recortaban los derechos cívicos se aprobaron por aclamación y al calor del ferviente del patriotismo que reclamaba una situación de amenaza nacional.

La seguridad nacional se convirtió en la principal preocupación para los Estados tras el 2001. La mayoría de los Estados imitaron el ejemplo de Estados Unidos. Los gobiernos utilizaron la omnipresente sensación de peligro posterior a los atentados del 11-S, convenientemente atizada por los medios de comunicación, para aumentar drásticamente los poderes policiales, de vigilancia y detención. En la cuestión de la vigilancia, básicamente se autorizó a los servicios secretos y la policía a recoger información sobre los ciudadanos sin estar sujetos siquiera a la supervisión judicial. ${ }^{15}$ En lo tocante a las detenciones, las leyes antiterroristas contemplaban la posibilidad de mantener en prisión sin cargos a un ciudadano durante un periodo de tiempo como medida de prevención. Aunque se transmitió a la población que el objetivo era luchar contra el terrorismo, el efecto fue la creación de un vasto aparato de seguridad que por muy escaso margen podía actuar con intenciones represoras. ${ }^{16}$

La estrategia de la lucha antiterrorista, además, incluyó operaciones encubiertas de "guerra sucia" contra el enemigo, ya fuera en el propio territorio o en territorio ajeno. ${ }^{17}$ Las actividades de la guerra sucia estaban dirigidas por los servicios secretos, que se

${ }^{14}$ Ibid., p. 232.

${ }^{15}$ Robert P. Abele, A User's Guide to the USA Patriot Act and Beyond, Lanham, University Press of America, 2005.

${ }^{16}$ Alrededor de 1200 extranjeros fueron arrestados y encarcelados en secreto en relación con la investigación de los ataques del 11-S. Amy Bartholomew (ed.), Empire's Law, Londres, Pluto, 2006.

${ }^{17}$ Laura Westra, Faces of State Terrorism, Leiden, Brill, 2012. 
fortalecieron con mayores efectivos y recursos con el objetivo de garantizar mayor protección al Estado. Además, se los dotó de mayor libertad de acción con el respaldo de las nuevas leyes de seguridad nacional. Las operaciones de "guerra sucia" consistían en infiltrar operativos en los países objetivo con el fin de realizar actos de provocación, sabotaje, asesinatos selectivos, secuestros, etc. ${ }^{18}$ Por lo general, esas operaciones encubiertas se efectuaban bajo el mando del ejército o los servicios secretos, y eran consideradas como materia de seguridad nacional, por lo que se hacía muy difícil para los poderes públicos y la justicia hacer un seguimiento de sus actividades y controlarlas.

\section{LA LUCHA ANTITERRORISTA EN LA AGENDA DE SEGURIDAD DE LA ONU}

Durante toda la década de 1990, y hasta los atentados del 11-S en 2001, combatir el crimen organizado fue el principal objetivo para la seguridad internacional. ${ }^{19}$ La lucha contra el crimen organizado adquirió una dimensión global en el año 2000 con la adopción de la Convención de la onU contra la delincuencia organizada transnacional. ${ }^{20} \mathrm{El}$ crimen organizado a nivel internacional en la Globalización estaba compuesto por una red ilegal que abarcaba todo el planeta con sus operativos, entrelazados en una compleja red de intereses. ${ }^{21}$ Estas redes obtenían sus ingresos, por un lado, del tráfico de mercancías y de la prestación de servicios ilegales (narcóticos, armas, residuos tóxicos, personas,

${ }^{18}$ Bartholomew, op. cit.

${ }^{19}$ La lucha contra el crimen organizado adquirió una dimensión global en el año 2000 con la adopción de la Convención de la onU contra la delincuencia organizada transnacional. Blanca Azcárate y Ferrán Montesa (eds.), El Atlas de las mundializaciones, Valencia, Mondiplo, 2011, p. 141.

${ }^{20}$ Azcárate y Montesa, op. cit., p. 141.

${ }^{21}$ Estas redes y su cooperación eran muy flexibles. Por ejemplo, en las actividades de contrabando o de inmigración clandestina cooperaban múltiples organizaciones. Generalmente, estas colaboraciones se disolvían después de obtener el beneficio económico. 
etc.) y, por otro lado, por medio de la adquisición de bienes ilegales y la venta de bienes legales.

La libre circulación de capitales y la intensificación de las relaciones comerciales habían facilitado la conexión entre los mercados y las organizaciones criminales. Con respecto al comercio, los traficantes aprovechaban la multiplicación de los intercambios que dificultaban la localización de los cargamentos de contrabando. Por su parte, la libre circulación de capitales y la desregulación de las transacciones financieras facilitaban el reciclaje de los beneficios generados por las actividades criminales. Estos beneficios se calcula que a principios del siglo xxi podían alcanzar alrededor de un billón y 1.5 billones de dólares. ${ }^{22}$ El reciclaje de estos ingresos a través del "blanqueo de capitales" favoreció una interpenetración, cada vez mayor, entre los capitales legales y los ilegales que retroalimentaba el sistema financiero.

Sin embargo, la presencia de estas redes criminales suponía una amenaza para el sistema internacional por diferentes motivos. En primer lugar, se consideraba probado que cuando se daba una alta proporción de crimen organizado y de actividades económicas sumergidas, miseria social y pérdida de la identidad social, los enfrentamientos violentos y el surgimiento del conflicto abierto eran altamente probables. Por ejemplo, los aspectos económicos del comercio de narcóticos y el lugar que éste llegó a ocupar en el centro de diversos conflictos armados hicieron del narcotráfico un maná financiero para las facciones en conflicto. De hecho, los principales cultivos de droga se encontraban en Estados pobres que experimentaban conflictos armados.

En segundo lugar, los negocios ilegales de variada condición alimentaban la corrupción, ya que cuando los negocios ilegales alcanzaban determinadas dimensiones se hacía prácticamente inevitable la connivencia con las autoridades para garantizar la prosperidad y los beneficios. Por lo tanto, este tipo de negocios fomentaba los sobornos a funcionarios de todo tipo. En lugares

${ }^{22}$ Martine Bulard; Alain Gresh, Philippe Rekacewicz, Catherine Samary y Olivier Zajec (eds.), El Atlas de las nuevas potencias emergentes, Valencia, Cybermonde, 2012, p. 51. 
donde las organizaciones criminales eran poderosas y el Estado débil dieron origen a lo que se denominó como "narco-Estados", en los que la estructura organizativa del Estado había sido completamente penetrada por las organizaciones criminales.

La penetración del sector legal de la sociedad por la criminalidad organizada se expandió por los cinco continentes. Los sectores económicos más penetrados por la criminalidad organizada eran la construcción, el turismo y el entretenimiento. Se atribuía, en promedio, 2\% del pIB de cada Estado a las actividades del crimen organizado. ${ }^{23}$ Sin embargo, los porcentajes variaban mucho de unos Estados a otros. Era extremadamente bajo en los países escandinavos, por ejemplo, mientras que alcanzaba altos niveles en Estados como Turquía, Brasil, la India, etc. En algunos como Rusia, Colombia y México, había pasado a ser parte permanente de la industria y el Estado. Finalmente, en otros como Albania y Zambia la interrelación entre la criminalidad organizada y el Estado era tan estrecha que ya no era posible definir dónde empezaba uno y dónde acababa el otro.

Por último, estaban los motivos morales. La prohibición mundial de ciertas drogas provenía de los movimientos sociales antiopio de finales del siglo xix, que consideraban el consumo de estas sustancias como una práctica destructiva para los individuos y deplorable para las sociedades. ${ }^{24}$ Sin embargo, la prohibición no evitaba el consumo clandestino y favorecía que las drogas alcanzasen un precio alto en el mercado, que reportaba unos beneficios elevados a los narcotraficantes. La producción de drogas proliferaba en el terreno fértil del subdesarrollo, donde el precio de los productos agrícolas era inferior y donde la autoridad de los Estados era débil, ${ }^{25}$ y sus mercados de consumo se expandían al ritmo del desarrollo económico en los Estados desarrollados.

${ }^{23}$ Rolf Uesseler, La guerra como negocio, Barcelona, Belacqua, 2007, p. 128.

24 Tres plantas proporcionan la mayoría de las drogas ilícitas. Se trata de la planta del opio (opio, morfina y heroína), el cannabis (marihuana y hachís) y la de coca (cocaína y crack), cuyas superficies cultivadas son las más extensas. Hay otras plantas como el khat que se cultivan a escala menor y su consumo es mayoritariamente local. Bulard, Gresh, Rekacewicz, Samary y Zajec, op. cit., p. 62.

${ }^{25}$ El cannabis se cultiva en todos los continentes. El cultivo del opio se con- 
Sin embargo, el 11-S alteró las prioridades en la agenda de seguridad de la onU y el terrorismo pasó a ser la principal amenaza por delante del crimen organizado. La principal dificultad para articular la lucha antiterrorista a nivel global en la onU residía en la aceptación de una definición de terrorismo válida para todos. La definición jurídica del concepto de terrorismo era tremendamente controvertida, ya que aspectos políticos condicionaban la descripción. Algunos juristas y gobiernos defendían la necesidad de diferenciar entre distintos tipos de terrorismo, en función de sus objetivos, de los métodos que empleaban o de las características del grupo. Sin embargo, otros consideran que no había distinción. Estas dificultades se veían acrecentadas por la necesidad de distinguir el fenómeno terrorista de otras formas de criminalidad con la que a veces podía llegar a confundirse.

Durante la Guerra Fría, numerosos actos susceptibles de ser tipificados como terroristas no lo fueron debido a la polémica entre los defensores del uso a la fuerza por parte de los movimientos de liberación nacional y los acérrimos detractores del terrorismo. Por lo tanto, solamente fue posible alcanzar acuerdos sectoriales. ${ }^{26}$ En dichos acuerdos se establecieron definiciones parciales acerca del terrorismo y se tipificaron determinadas actividades como terroristas. En concreto, la dificultad para establecer una definición del terrorismo que no se confundiera con las luchas de autodeterminación de los pueblos colonizados bloqueaba cualquier acuerdo, ya que la onu reconocía como un derecho fundamental el recurso a la lucha armada en casos justificados. De la misma forma, debía distinguirse de las actividades de los grupos guerrilleros o de las fuerzas armadas de los Estados. Estos actuaban en el marco de un conflicto bélico y se les debía aplicar el derecho de los

centra especialmente en Asia (Afganistán y Birmania), pero está implantada en América Latina desde el comienzo del siglo xx. En cuanto a la coca, se trata del cultivo más endémico, ya que se limita a la región andina (Bolivia, Colombia y Perú). Bulard, Gresh, Rekacewicz, Samary y Zajec, op. cit., p. 62.

${ }^{26} \mathrm{El}$ Convenio internacional contra la toma de rehenes (1979); el Protocolo de Montreal referido a la seguridad en los aeropuertos (1988); el Convenio sobre la seguridad marítima (1988). Luis M. Hinojosa, La financiación del terrorismo y las Naciones Unidas, Madrid, Tecnós, 2008, p. 16. 
conflictos armados. Mientras que las actividades de terrorismo correspondían al derecho penal.

En la década de 1990, con la caída del bloque soviético se produjo un cambio en el panorama. En 1994, la Asamblea General aprobó la Resolución 49/60, que marcó un punto de inflexión en su postura respecto al terrorismo. En dicha resolución se afirmaba contundentemente que los actos terroristas debían considerarse como criminales e injustificables, al margen de quien los cometa y sus motivaciones. En 1996, la Asamblea General aprobó otra resolución complementaria de la de 1994. En esta resolución se proponía un conjunto de medidas concretas y se creaba el "Comité Especial para los asuntos referidos al terrorismo". ${ }^{27}$ Desde el año 2000 , este comité ha trabajado en la elaboración de un convenio internacional general referido a la represión del terrorismo. ${ }^{28}$

La cooperación internacional en la lucha contra el terrorismo experimentó un impulso decisivo con la presión política proveniente de Washington y la trascendencia mediática que generaron los ataques del 11-S. Sin embargo, a pesar del impulso que supuso la lucha antiterrorista desencadenada en 2001, las negociaciones en relación con este Convenio general se toparon con los mismos obstáculos que en el pasado imposibilitaron un consenso internacional sobre el terrorismo, la definición de terrorismo. Ante la dificultad para llegar a un acuerdo en la Asamblea General, el Consejo de Seguridad tomó la iniciativa. Debido al temor a que las discusiones sobre la definición de terrorismo hubiesen demorado la adopción de medidas concretas y creado divisiones entre los Estados miembros de la onU, el Consejo de Seguridad comenzó a adoptar medidas urgentes contra el terrorismo sin esperar a contar con una definición del fenómeno, a pesar de las debilidades jurídicas que esta decisión ocasionaba.

${ }^{27}$ Del trabajo de este comité surgieron: el Convenio internacional para la represión de los atentados cometidos con bombas (1997); el Convenio internacional para la represión de la financiación del terrorismo (1999); el Convenio internacional para la represión de los actos de terrorismo nuclear (2005). Hinojosa, op. cit., p. 19.

${ }^{28}$ Siguiendo el mandato establecido por la Resolución 51/210. Hinojosa, op. cit., p. 20. 
El Consejo de Seguridad había comenzado a desempeñar una función activa en relación con el terrorismo desde 1989. Como respuesta a los atentados contra los vuelos de Pan-Am (1988) y UTA (1989), el Consejo de Seguridad aprobó sanciones contra Libia por su falta de colaboración en las investigaciones. A partir de aquí, el terrorismo fue cobrando protagonismo en las actividades del Consejo de Seguridad. La imposición de sanciones a Sudán por su falta de colaboración en relación con la investigación de los atentados de Nairobi y Dar es Salaam (1998), la condena al apoyo exterior de las actividades terroristas en Kosovo (1998) y la saga de resoluciones contra Afganistán por su colaboración con Al-Qaeda (1998-2000) son una muestra de la atención dedicada por el Consejo de Seguridad al terrorismo antes del 11-S.

\section{EL 1 1-S CAMBIA LA AGENDA DE SEGURIDAD Y RECORTA LAS LIBERTADES INDIVIDUALES}

El 11-S marca un antes y un después en el tratamiento del terrorismo por el Consejo de Seguridad. En ausencia de otros mecanismos internacionales más eficaces, el Consejo de Seguridad decidió redefinir su papel y sus funciones apoyándose en el capítulo viI de la Carta de Naciones Unidas. ${ }^{29}$ Según la Carta de las Naciones Unidas, esta institución sólo puede hacer uso de estos poderes previa constatación de la existencia de una amenaza para la paz, un quebrantamiento de la paz o un acto de agresión. Por lo que el Consejo de Seguridad definió el terrorismo como una amenaza para la paz y la seguridad internacionales a partir de 2001.

En este sentido, el Consejo emitió en 2001 la Resolución 1373, que establecía obligaciones de carácter general y con aplicación universal en relación al problema del terrorismo. La resolución imponía la adopción de reformas legislativas internas de carácter penal, administrativa y procesal. Para verificar la aplicación de esta resolución se creó el "Comité contra el terrorismo", encargado de realizar

${ }^{29}$ Los poderes del Consejo de Seguridad quedan definidos en los capítulos vI, VII, viII y XII de la Carta de Naciones Unidas. Hinojosa, op. cit., p. 133. 
evaluaciones de expertos en los Estados y prestar a sus gobiernos asistencia técnica en la lucha contra el terrorismo.

En 2006, la postura de la Asamblea General se acercó a la del Consejo de Seguridad. La Asamblea presentó una "Estrategia global de las Naciones Unidas contra el terrorismo", mediante la Resolución 60/288. En ella, se adoptaba la misma fórmula de condena del terrorismo que empleaba el Consejo de Seguridad, calificándolo como una de las amenazas más graves para la paz y la seguridad internacionales. ${ }^{30}$ A pesar de todo, seguía sin haber en la onU una definición única y clara del concepto de terrorismo. De hecho, hacia finales de la primera década del siglo xxi, el impulso que había cobrado la cooperación internacional en materia de terrorismo tras el 11-S comenzó a diluirse, debido en buena parte a los excesos de la ocupación estadounidense de Iraq.

Por otro lado, la potestad que se había arrogado el Consejo de Seguridad en su lucha contra el terrorismo, indefinida en el tiempo, contradecía la naturaleza primigenia de este organismo que se creó para solventar crisis excepcionales y concretas. El Consejo de Seguridad afrontaba un nuevo concepto de seguridad internacional mucho más diverso y complejo. La progresiva extensión del concepto de amenaza para la paz obligó al Consejo a ampliar el abanico de medidas aplicables, en un intento de adecuar su intervención a las necesidades de cada caso. En 2006, el Consejo de seguridad adoptó una serie de principios recogidos en el mencionado "deber de protección", ${ }^{31}$ que estipulaba la obligación de la onu de proteger a las poblaciones de sus agresores. En 2009, la Asamblea de la ONU aceptó este principio y reconoció la preeminencia del Consejo de Seguridad en las cuestiones relativas a la seguridad internacional. ${ }^{32}$

Una de las medidas contra el terrorismo adoptadas por el Consejo de Seguridad, que más polémica despertaron, fueron las denominadas "sanciones inteligentes" que se dirigían contra individuos

${ }^{30}$ Hinojosa, op. cit., p. 22.

31 http://www.un.org/es/preventgenocide/adviser/responsibility.shtml (3/ $6 / 15)$.

${ }^{32}$ Bulard, Gresh, Rekacewicz, Samary y Zajec, op. cit., p. 143. 
y no contra Estados. La Resolución 1333 en 2000 supuso el primer paso relevante en esta dirección. Además de reforzar las medidas restrictivas contra los talibanes, la resolución imponía que todos los gobiernos congelasen los fondos y finanzas de Bin Laden y otras personas asociadas con él. Tras el 11-S, las Resoluciones 1373 (2001) y 1390 (2002) confirmaron y reforzaron esta tendencia a sancionar a individuos y entidades no estatales. ${ }^{33}$

El "Comité 1267", dependiente del Consejo de Seguridad, fue designado para desempeñar las funciones de la lucha contra el terrorismo en la onU. Este comité se había creado en 1999 con la Resolución 1267 dirigida a combatir las actividades de Al-Qaeda. El trabajo de este comité se alimentaba de las informaciones de los servicios de inteligencia de los Estados miembros del Consejo de Seguridad, principalmente de Estados Unidos. Sin embargo, el secretismo de estas informaciones dotaba de una opacidad intolerable a las medidas adoptadas por dicho comité. La principal tarea del comité consistía en elaborar una lista que se renovara periódicamente de individuos o entidades relacionadas con el terrorismo, que fueran susceptibles de aplicárseles las sanciones del Consejo de Seguridad.

El procedimiento empleado para incluir los nombres en dicha lista se iniciaba con la propuesta de alguno de los Estados, basándose en informaciones de inteligencia propias que no se podían compartir. Lo normal a continuación es que los demás Estados del Consejo de Seguridad aceptasen la propuesta sin cuestionarse si la acusación era válida o no. Salvo que hubiera algún interés particular en una persona o entidad determinada, la decisión se tomaba por consenso. De hecho, la mayoría de las propuestas se han aprobado automáticamente y sin debate.

Es evidente que un procedimiento de este tipo permite al comité actuar con gran agilidad, pero también vulnera las más elementales garantías de derechos individuales, ya que no hay una investigación sobre la legitimidad de la acusación y el afectado no tiene posibilidad de recurrir la decisión. ${ }^{34}$ Todo el procedimiento

${ }^{33}$ Hinojosa, op. cit., pp. 122-123.

${ }^{34}$ Las críticas a esta situación motivaron que el Consejo de Seguridad emitie- 
carece de garantías judiciales y se basa exclusivamente en criterios políticos. De manera que todo el proceso de elaboración de estas listas de terroristas está impregnado de una dosis considerable de arbitrariedad y se proyecta toda una sombra de ilegitimidad sobre las actividades del Comité 1267.

La internacionalización de las medidas legales adoptadas en la lucha contra el terrorismo se llevó por delante garantías democráticas fundamentales. Es una realidad que muchos gobiernos han aprovechado las reformas legislativas antiterroristas patrocinadas por la ONU para recortar de manera significativa derechos fundamentales. En definitiva, con la aplicación de la lucha antiterrorista, se restringieron las libertades individuales; en algunos casos, incluso, se generalizaron prácticas condenadas por el derecho internacional, como las relativas al trato de prisioneros y el uso de la tortura. Además, los delitos de terrorismo se hicieron extensivos a cualquier forma de oposición en contra de los gobiernos. ${ }^{35}$

La lucha antiterrorista no puede ser el principio organizador central de la política de seguridad internacional. Dicha política ha de tener un alcance político y social más amplio, y debe abarcar iniciativas destinadas a solucionar los problemas subyacentes que contribuyen a alimentar el terrorismo. Cuando el estado de excepción se convierte en permanente, la democracia se transforma en dictadura. ${ }^{36}$ Por este motivo, la lucha contra el terrorismo puso en marcha ciertos procesos que se refuerzan entre sí y corroen el actual ordenamiento del sistema internacional. Uno de los efectos fue que la represión generase más terrorismo, lo que a su vez creaba más represión y así sucesivamente. Por otro lado, al identificar a los terroristas como el principal enemigo militar de los Estados, en lugar de considerarlos delincuentes y perseguirlos con medios policiales exclusivamente, se les confirió a los terroristas un estatus político que les beneficiaba. ${ }^{37}$

ra la Resolución 1730 (2006) en la que se aprobaba un procedimiento para la supresión de nombres de la lista. Hinojosa, op. cit., p. 131.

${ }^{35}$ Bartholomew, op. cit.

${ }^{36}$ Como han demostrado numerosos teóricos del derecho. Giorgio Agamben, Estado de excepción, Madrid, Pre-textos, 2003.

${ }^{37}$ Mary Kaldor, El poder y la fuerza, Barcelona, Tusquets, 2010, p. 26. 


\section{El unilateralismo de Estados Unidos y el nUevo SISTEMA DE SEGURIDAD}

La lucha contra el terrorismo implicaba la adhesión incondicional al gobierno de Estados Unidos y no la implicación responsable de los demás gobiernos con la legalidad internacional y los derechos humanos. Esto significaba en la práctica la sustitución del sistema de seguridad global por un nuevo sistema de seguridad unilateral. El abandono, por parte de Washington, de la estrategia de seguridad global a través de la onu delataba la incapacidad de Estados Unidos para imponer sus criterios y era una muestra más del debilitamiento de la hegemonía estadounidense. Además, la sobrecargada agenda internacional del líder global se complicaba con una situación económica cada vez más sombría.

Como parte de su lucha antiterrorista, el gobierno de Estados Unidos desarrolló una agresiva política exterior que culminó en una sucesión de agresiones bélicas contra otros Estados, Afganistán (2001) e Iraq (2003). En el caso de Afganistán, Washington recurrió a su derecho a la legítima defensa para legitimar la invasión del país asiático. Efectivamente, el derecho internacional recogía desde antiguo que los Estados tenían derecho a emplear la fuerza en caso de defensa propia. ${ }^{38}$ La defensa propia quedaba restringida a la respuesta de un ataque armado previo y requería la autorización del Consejo de Seguridad. Washington obtuvo la autorización del Consejo de Seguridad de manera urgente, por lo que el ataque a Afganistán fue legal. A pesar de su legalidad, surge la duda de si fue un ataque legítimo, ya que el atacante del 11-S no era el Estado afgano, sino la organización terrorista Al-Qaeda. Ni siquiera los terroristas que participaron eran afganos.

Para justificar su agresión a Iraq, el gobierno de Estados Unidos rescató el concepto de la "guerra preventiva". ${ }^{39}$ La "guerra

${ }^{38}$ La excepción al uso de la fuerza en caso de autodefensa quedó delimitada en el artículo 51. El artículo 51 deja claro que en un caso de autodefensa, la responsabilidad principal le corresponde al Consejo de Seguridad y no a la víctima del ataque. Richard Falk, La globalización depredadora: una crítica, Madrid, Siglo XXI España, 2002, p. 249.

${ }^{39}$ Este concepto no se empleaba en las Relaciones Internacionales desde los 
preventiva" se basaba en el principio de legítima defensa, pero variaba su esencia, al reservar el derecho al supuesto agredido a actuar antes de que se produjera el ataque. Obviamente, era imposible probar las intenciones del supuesto agresor si no se había producido el ataque, lo que daba lugar a interpretaciones que podían justificar la agresión, pero legitimándola como una autodefensa. ${ }^{40}$

Esta actitud unilateral de Washington en la política internacional ya había comenzado antes del 11-S. El rechazo a sancionar el Tribunal Penal Internacional (TPI) y otras posturas aislacionistas adornadas con la arrogancia característica del gobierno de Bush precipitaron que en mayo de 2001 los aliados europeos de Estados Unidos se unieran a otros Estados en una votación para negarse a reelegir a Estados Unidos como miembro de la Comisión de los Derechos Humanos de la ONU. El Congreso estadounidense respondió votando no pagar las cuotas a la onU. ${ }^{41}$ En 2002, Washington, de nuevo unilateralmente, denunció al "eje del mal”, formado por Iraq, Irán y Corea del Norte, como una amenaza para su seguridad nacional y los declaró sus principales enemigos sin estar en guerra legalmente con ellos.

El plan de "Estrategia de Seguridad Nacional de los Estados Unidos" aprobado en vísperas de la invasión de Iraq, y que sería conocido como la "Doctrina Bush", establecía tres principios clave para la política estratégica de Estados Unidos. ${ }^{42}$ El primero era la perpetuación de un dominio militar global sin par, de manera que no se permita que ninguna nación rivalice o amenace a Estados Unidos. El segundo era la disposición de Estados Unidos a enfrascarse en ataques militares "anticipatorios" contra los Estados o fuerzas de cualquier lugar del mundo que se considerasen una

años previos a la Segunda Guerra Mundial, cuando fue justificado por la diplomacia del Tercer Reich.

40 Allen Buchanan y Robert O. Keohane, "The Preventive Use of Force: A Cosmopolitan Institutional Proposal”, Ethics Eं International Affairs, vol. 18, núm. 1, 2004, pp. 1-22.

${ }^{41}$ Joseph S. Nye, La paradoja del poder norteamericano, Madrid, Santillana, 2003, p. 216. $6 / 15)$.

${ }^{42}$ http:/ / www.usembassy-mexico.gov/bbf/ej/EJ\%201202sp_estrategia.pdf (3/ 
amenaza para la seguridad del país, de sus fuerzas y de sus instalaciones en el extranjero o de sus amigos o aliados. El tercero era la firme determinación a defender sus intereses en política exterior de manera unilateral si era necesario. ${ }^{43}$

El unilateralismo estadounidense provocó el derrumbe del sistema de seguridad global basado en un marco multilateral representado por la onu. ${ }^{44}$ Sobre todo, la invasión de Iraq (2003), llevada a cabo por Estados Unidos sin la aprobación de la onU, inauguró la transición hacia un nuevo sistema de seguridad internacional basado, de nuevo, en las competencias nacionales de cada Estado. Este sistema de seguridad global basado en la onu se había establecido con la Guerra del Golfo (1991) y había sido concebido para superar la estructura de la Guerra Fría basada en bloques de alianzas militares, como la OTAN y el Pacto de Varsovia.

Washington comenzó a aplicar su propio plan de seguridad nacional, apoyándose cada vez más en sus aliados de la oTAN y prescindiendo de la onU. La Doctrina Bush contemplaba la posibilidad de que si en el seno de estos OIG Washington no lograba el respaldo necesario, sus planes de seguridad nacional se aplicarían de todas maneras. La invasión de Afganistán contó con el apoyo incondicional de la comunidad internacional, pero la invasión de Iraq tropezó con la oposición de la absoluta mayoría en la ONU. De forma que para sortear esta dificultad, Estados Unidos forjó un eje militar en estrecha colaboración con Gran Bretaña y otros aliados circunstanciales. El gobierno de Estados Unidos aplicó esta misma táctica de composición de alianzas escogidas para la ocasión en otras cuestiones de controversia internacional. Estas alianzas eran más manejables y dotaban de respaldo internacional a las actuaciones del gobierno Bush. Sin duda, estas alianzas ganaron en rapidez de respuesta, pero eran mucho menos significativas desde el punto de vista político, ya que no eran integradoras.

${ }^{43}$ Bartholomew, op. cit., p. 128.

${ }^{44}$ Ken Booth y Timothy Dunne (ed.), Worlds in Collision, Nueva York, Palgrave Macmillan, 2002. 
Esta nueva realidad fomentó la proliferación de diversas alianzas militares de ámbito regional ${ }^{45}$ (OCS, ${ }^{4}{ }^{6}$ OTSC, 47 Unasur, $4^{8}$ UA, ${ }^{49}$ etc.). La otAn sería la más potente armamentísticamente y la única de estas alianzas militares con una capacidad de acción global. ${ }^{50}$ Para asegurarse un amplio campo de acción, la OTAN varió sus estatutos en 1999, con que dejó de estar limitada al ámbito geográfico del Atlántico Norte y sus riberas, para pasar a contemplar todo el orbe como su límite geográfico de intervención armada. La ampliación geográfica y de atribuciones de la OTAN ha reforzado el liderazgo de Estados Unidos y ha dotado a la OTAN de soberanía propia con respecto a la onU. La ampliación de su campo de operaciones al escenario global la faculta para operaciones en cualquier rincón del orbe, lo cual la convierte en una alternativa a la ONU para las intervenciones armadas. Por otro lado, la ampliación de Estados miembros de la otan,${ }^{51}$ con la inclusión de aliados en Europa Oriental, logró casi aislar a Rusia y sometió la política de seguridad de la Unión Europea a las decisiones de la organización.

\section{REgRESO AL SISTEMA DE ALIANZAS}

La nueva situación devolvía al sistema de seguridad internacional a un estadio anterior al del sistema global basado en la ONU. El nuevo sistema de seguridad basado en las alianzas militares carecía de una normativa internacional que lo regulase. Tampoco estaba sujeto a la legitimidad de instancias internacionales. Básicamente,

${ }^{45}$ Barry Buzan y Ole Waever, Regions and Powers: The Structure of International Security, Cambridge, Cambridge University Press, 2003.

${ }^{46}$ Organización de Cooperación de Shanghái.

47 Organización del Tratado de Seguridad Colectiva.

${ }^{48}$ Unión de Naciones Suramericanas.

${ }^{49}$ Unión Africana.

${ }^{50} \mathrm{El}$ presupuesto militar de la ocs, la segunda más importante, es netamente inferior al de la отAn en una relación de 1 a 8 aproximadamente. Bulard, Gresh, Rekacewicz, Samary y Zajec, op. cit., p. 134.

${ }^{51}$ En 1994 el gobierno de Estados Unidos promovió la Partnership for Peace, que era una avanzadilla para la ampliación de la OTAN a los Estados de Europa Oriental. La ampliación se efectuó en 1999. 
se legitimaba según las decisiones de los principales gobiernos y su aplicación se hacía de manera unilateral. Desgraciadamente, estas políticas de seguridad iban en detrimento de las normas democráticas, los derechos y las libertades universales. ${ }^{52}$ La nueva política de seguridad internacional se estaba aplicando al margen de la ONU, desplazaba las deliberaciones en la Asamblea General e ignoraba la posibilidad de veto de alguno de los miembros del Consejo de Seguridad.

Por otra parte, el resto de potencias imitaron la actitud unilateral de Estados Unidos, con lo cual se disgregó el sistema de seguridad internacional instaurado en la Globalización y se regresó a un sistema en el que cada Estado elaboraba su propia política de seguridad nacional. ${ }^{53}$ Esto tuvo como consecuencia un incremento del gasto militar a nivel mundial que creció una media de $44.7 \%$ desde antes del 11-S (1999) hasta $2008 .{ }^{54} \mathrm{Si}$ observamos la tendencia de los gastos en armamentos durante el periodo de la Globalización, podemos notar que tras el final de la Guerra Fría hay un claro descenso en los presupuestos de defensa de las principales potencias, el cual es espectacular en el caso de Rusia.

En los años siguientes se mantiene una sostenida tendencia a la baja hasta finales de los años noventa. Entre 1997 y 1998 se produce un repunte en el gasto militar que se va a disparar a partir de 2001, como en el caso de Estados Unidos y Rusia. ${ }^{55}$ Ya en 2005, la evolución de los gastos militares supera los niveles de la Guerra Fría (excepto en el caso de Rusia, Alemania y Francia). En el caso de Estados Unidos el gasto alcanza los 478100 millones de

${ }^{52}$ Bartholomew, op. cit.

${ }^{53}$ Barry Buzan y Eric Herring, The Arms Dynamic in World Politics, Boulder, Lynne Rienner, 1998.

${ }^{54}$ Incremento en el periodo de 1999-2008: China (194\%); Rusia (173\%); Estados Unidos (66,5\%); la India (44\%); Brasil (29.9\%); Unión Europea (5\%). Marie-Françoise Durand, Philippe Copinschi, Benoît Martin y Delphine Placidi (eds.), Atlas de la globalización: comprender el espacio mundial contemporáneo, Universitat de Valencia, 2008.

${ }^{55}$ Los gastos militares de Estados Unidos en 2001 representaron 36\% de los gastos militares mundiales. Los gastos de la OTAN en su conjunto representaban el $63 \%$. Eric Toussaint, La bolsa o la vida. Las finanzas contra los pueblos, San Sebastián, Edt. Tercera prensa-Hirugarren prensa, 2002, pp. 206-207. 
dólares. ${ }^{56}$ Otros Estados que han incrementado sustancialmente su gasto son: China, Irán, Siria, la India, Israel, Turquía, Pakistán, Japón, etc.

Buena parte del gasto se ha incrementado por el creciente coste de las nuevas tecnologías. Los armamentos se han desarrollado rápidamente en los últimos años con el tirón de las nuevas tecnologías y han provocado la llamada "revolución en asuntos militares". ${ }^{57}$ Cada nueva generación en armamentos es de tres a cinco veces más caro que la generación anterior. ${ }^{58}$ Esto se debe al creciente e inevitable perfeccionamiento de las armas. La tendencia de la producción armamentística se dirige hacia armas más complejas, más caras y menos numerosas. Esta tendencia ha hecho que los gastos en defensa absorban una proporción cada vez mayor de los presupuestos oficiales y del PIв. ${ }^{59}$ Más aún, el gasto en armas se ha elevado más deprisa que la economía global y la mayoría de las economías nacionales. Los precios de las armas suben más rápido que el ritmo de la inflación. ${ }^{60}$

Sin embargo, el incremento del gasto militar también tiene que ver con el interés de dotarse de unas fuerzas armadas mejor preparadas en caso de conflicto. El gasto militar mundial en 2008 fue de 1.464 billones de dólares, lo que representaba un $2.5 \%$ del producto mundial bruto y 202 dólares per cápita. El incremento medio anual del gasto en armamento giraba en torno al $5 \%$. Estados Unidos estaba a la cabeza del gasto en defensa con más de

${ }^{56}$ Cifra superior a los 431300 millones de dólares que gastaba al final de la Guerra Fría. SIPRI, Yearbook 2005. Armaments, Disarmament and International Security, Nueva York, Oxford University Press, 2005.

${ }^{57}$ La "revolución en los asuntos militares" (RMA: Revolution in Military Affaire) consiste en la mejora de las comunicaciones y el procesamiento de la información que permiten un mayor control del mando y mejor coordinación de las operaciones. Además de implementar progresos en la detección y la vigilancia que han mejorado los efectos de la localización del objetivo. Bulard, Gresh, Rekacewicz, Samary y Zajec, op. cit., p. 138.

${ }^{58}$ Paul Kennedy, Auge y caída de las grandes potencias, Barcelona, Random House, 2011, p. 751.

${ }^{59}$ La producción de un nuevo caza de combate para la Air Force puede absorber el presupuesto anual del Pentágono. Kennedy, op. cit., p. 690.

${ }^{60}$ Kennedy, op. cit., p. 751. 
606000 millones de dólares invertidos en 2009 y un incremento de $59 \%$ desde 2001. El resto de los Estados de la OTAN gastaron ese mismo año 311000 millones de dólares, con lo que sumadas ambas cantidades suponían más de dos terceras partes del gasto en defensa mundial. Después de Estados Unidos, los Estados que más gastaron en armamento fueron, por orden de importancia, Gran Bretaña, China, Francia y Japón. ${ }^{61}$ Por regiones geográficas, los mayores incrementos entre 1998 y 2007 se produjeron, por orden de importancia, en Europa Oriental (162\%), América del Norte $(65 \%)$, Oriente Medio (62\%), Sudeste Asiático (57\%), África (51\%), Extremo Oriente (51\%), América Central (14\%) y Europa Occidental $(6 \%){ }^{62}$

En cuanto a los tratados internacionales sobre desarme, la última conferencia de la onu sobre desarme en 2005 fue un manifiesto fracaso y concluyó sin un solo compromiso e inclusive sin declaración. ${ }^{63}$ Durante el periodo de la Globalización, se firmaron diversos tratados de reducción de armamentos sectoriales, como el START I $^{64}$ (1991); su actualización, el START II (1993); y el SORT ${ }^{65}$ (2001). Sin embargo, Estados Unidos se retiró unilateralmente en 2002 del tratado Aвм, ${ }^{66}$ que se firmó entre la Unión Soviética y Estados Unidos en 1972 y que había sido uno de los pilares fundamentales de la política de apaciguamiento de la Guerra Fría. Detrás de esta decisión estaba la voluntad de Washington de desarrollar su proyecto de la "guerra espacial", ${ }^{67}$ que se basaba en el despliegue de una red de misiles estratégicos que formarían un

${ }^{61} \mathrm{El}$ acuerdo alcanzado entre Estados Unidos y Japón en 1996 autorizó, a partir de 1997, la ampliación del ejército japonés y su participación en misiones humanitarias fuera de su territorio. Yolanda Fernández, China. La construcción de un Estado moderno, Madrid, Catarata, 2001, p. 165.

62 Para todas las cifras. SIPRI, Yearbook 2009. Armaments, Disarmament and International Security, Nueva York, Oxford University Press, 2009.

${ }^{63}$ Rafael Poch, La actualidad de China, Barcelona, Crítica, 2009, p. 75.

${ }^{64}$ START (Strategic Arms Reduction Treaty): Tratado de Reducción de Armamento Estratégico.

${ }^{65}$ soRT (Strategic Offensive Reductions Treaty): Tratado de Reducciones de Ofensivas Estratégicas.

${ }^{66}$ ABM (Anti-Ballistic Missile Treaty): Tratado sobre misiles antibalísticos.

${ }^{67}$ Es un proyecto militar que prevé el desarrollo de armamento de largo al- 
escudo antimisiles. El rechazo de Washington del ABM provocó la respuesta de Rusia, que se retiró del START II. El nuevo gobierno estadounidense de Obama logró en abril de 2010, después de arduas negociaciones, que se firmara entre Estados Unidos y Rusia el nUevo START III que reemplazaba al START II.

\section{ObJetivos y RESUltados DE LA LUCHA ANTITERRORISTA}

La lucha antiterrorista buscaba garantizar la seguridad nacional, aunque fuera actuando en el escenario internacional. El principal enemigo declarado era el terrorismo, contra el cual era preciso desencadenar una guerra total de extensión indefinida en el tiempo y en el espacio. El núcleo de la lucha antiterrorista era la "guerra preventiva”, que implicaba atacar al terrorismo en el lugar en que se gesta, antes de ser atacados en el propio territorio. ${ }^{68} \mathrm{La}$ justificación esencial para este tipo de intervenciones armadas fuera del territorio propio era que se trataba de herramientas al servicio de la difusión de la paz y la democracia. Por tanto, gracias al uso de la fuerza, se podría alcanzar un sistema más seguro y próspero. Esta nueva justificación sucedía a un planteamiento similar y anterior basado en las intervenciones humanitarias. La diferencia primordial consistía en que las intervenciones humanitarias solamente eran justificables para detener o prevenir catástrofes humanitarias a gran escala; o para proteger los derechos humanos; o facilitar la ayuda humanitaria donde no era posible de otra manera. ${ }^{69}$ En todos estos casos se trataba de una actuación como reacción frente a unos acontecimientos.

En cambio, el nuevo concepto de seguridad internacional alertaba sobre los Estados fallidos, donde los terroristas podían hacerse con el control y extender el caos a Estados vecinos. Para prevenir la extensión de este cáncer, las intervenciones armadas antiterroristas

cance que traspasaría la atmósfera y que los límites impuestos por el ABм impedía desarrollar.

68 Alfonso Merlos, Terror.com, Universidad de Navarra, 2008.

${ }^{69}$ Michael Heazle e Iyanatul Islam, Beyond the Iraq War, Northampton, Edward Elgar, 2006, p. 1-3. 
cumplían con la función de extirpar el mal a tiempo. Es decir, se trataba de una actuación previa a los posibles acontecimientos. Lógicamente, la arbitrariedad de esta justificación, basada no en hechos, sino en presunciones, planteaba serias dudas con respecto a su legitimidad. Para legitimar esta controvertida medida, se estimuló a la opinión pública, desde los medios de comunicación, con la exageración de la amenaza terrorista. Las grandes corporaciones mediáticas adoptaron un discurso simplificador y tendencioso que exageraba la importancia de los grupos terroristas y enfocaba casi exclusivamente el fenómeno sobre el terrorismo de origen islamista.

Esta estructura del sistema de seguridad internacional reafirmaba el papel de Estados Unidos, como sostenedor indispensable de toda la estructura de seguridad global y relegaba cualquier alternativa a la hegemonía estadounidense a un plano poco realista. En definitiva, el sistema de seguridad internacional implementado por Estados Unidos tras el 11-S reafirmó brevemente su posición hegemónica global. Bajo esta política de seguridad se asignaron nuevas misiones a la OTAN, que estaban dirigidas por Estados Unidos. Los Estados aliados que participaban en estas operaciones quedaban subordinados a Estados Unidos, ya que las estructuras organizativas y de mando de la otan reservan el papel de liderazgo a los estadounidenses. Para defender sus intereses propios, los Estados aliados de Estados Unidos debían recurrir también a la oTAN, lo cual devolvió a Washington el papel protagonista en el sistema de seguridad que había perdido con el final de la Guerra Fría y la lucha contra el comunismo.

Sin embargo, el propio ejercicio de la hegemonía y de administrar la seguridad a nivel global le han acarreado hostilidades en todo el mundo a Estados Unidos. El doble rasero empleado por Washington y el voluntario aislamiento legalista han anulado la imagen de Estados Unidos como estandarte de los derechos humanos. Por otra parte, el recurso a la guerra preventiva sin autorización ha debilitado la autoridad del Consejo de Seguridad de la onU. El mal uso del poder hegemónico de Estados 
Unidos ha socavado su capacidad para movilizar apoyos internacionales. ${ }^{70}$ Es decir, ha debilitado su propia hegemonía.

En un primer momento, el recurso al nacionalismo y al alarmismo frente al terrorismo logró movilizar a la sociedad estadounidense y a la sociedad internacional. Sin embargo, en el mediano plazo, su lucha antiterrorista de ámbito global fue percibida como arbitraria e interesada por buena parte de la sociedad internacional y desgastó la confianza en el sistema de seguridad liderado por Estados Unidos. En el largo plazo, también se debilitó el apoyo de la sociedad estadounidense que comenzó a percibir la lucha antiterrorista en los mismos parámetros que el resto de la sociedad internacional.

Otro efecto de la lucha antiterrorista fue que la amenaza de intervención militar por parte del centro del sistema estimuló a muchos Estados de la periferia a iniciar una carrera armamentística con la esperanza de salvaguardar su soberanía nacional e independencia. A su vez, esta proliferación armamentística aumentaba la sensación de inseguridad en el centro del sistema y motivaba la necesidad de las intervenciones militares contra los Estados "problemáticos" que podían representar una amenaza. Por otra parte, la incapacidad del ejército de Estados Unidos para someter Afganistán e Iraq puso en entredicho su potencia militar, última garantía del orden global.

Por tanto, el recurso a focalizar la atención sobre el terrorismo como el principal problema de la agenda global sólo resultó rentable políticamente en el corto plazo. La gran ventaja de la lucha antiterrorista era su planteamiento simple. Demonizando a un enemigo desconocido y agitando miedos vagamente definidos, se logró catalizar el apoyo y la unidad popular. Sin embargo, en el largo plazo, dicho recurso carecía de permanencia y causaba división en la comunidad internacional, ya que el planteamiento de la lucha antiterrorista estaba impregnado de sentimientos nacionalistas y de intolerancia hacia otras posturas discrepantes. Por otro lado, la efectividad de la lucha antiterrorista ha sido prácticamente

${ }^{70}$ Brzezinski, op. cit., p. 23. 
nula, cuando no contraproducente..$^{71}$ Un estudio de 2007 calculaba que el número de ataques terroristas en el mundo desde el inicio de la invasión de Iraq se había multiplicado por siete. ${ }^{72}$ Por otra parte, han quedado sin esclarecerse las vinculaciones de determinados grupos terroristas con Estados y corporaciones, o los propios actos terroristas desempeñados por los Estados en el desarrollo de la guerra sucia contra el terrorismo. ${ }^{73}$

El gobierno de Obama, si bien se distanció de la retórica mesiánica del gobierno de Bush, continuó con la lucha contra el terrorismo. Se pueden apreciar diferencias en los métodos de aplicación de la lucha contra el terrorismo entre las dos administraciones, pero los objetivos son los mismos. En concreto, el gobierno de Obama ha aflojado en lo que respecta a la presencia del ejército en los frentes de guerra. Sin embargo, ha intensificado la actividad de las agencias de los servicios secretos y el empleo de la guerra sucia. La intensificación de las prácticas de espionaje ha ejercido tensiones internacionales de envergadura similar a las acciones militares perpetradas en el periodo de Bush. En concreto, las escuchas y el espionaje realizado por la NSA contra los gobiernos aliados europeos han tensado las relaciones entre Washington y Bruselas. En este aspecto, las revelaciones del agente renegado Snowden han aportado luz sobre estas actividades encubiertas.

\section{LA EXPLICACIÓN CON TRASFONDO POLÍTICO}

Como hemos visto, la lucha antiterrorista tuvo consecuencias importantes en la estructura del sistema internacional, no en sí beneficiosas. Aparte de los escasos resultados que obtuvo la lucha antiterrorista en su objetivo de extirpar el terrorismo, tuvo consecuencias desastrosas en otros ámbitos. El recorte de libertades

${ }^{71}$ Según Peter Bergen (especialista en terrorismo): "2003 presenció la mayor incidencia de atentados terroristas significativos de las últimas dos décadas, cifra que después, en 2004, asombrosamente se triplicó”. Chomsky, op. cit., p. 33.

${ }^{72}$ Naomi Klein, La doctrina del shock, Barcelona, Paidós, 2010, p. 555.

73 Paul Todd y Jonathan Bloch, Global Intelligence, Nueva York, Zed Books, 2004. 
individuales y garantías democráticas dañaba seriamente los fundamentos mismos del sistema internacional. Por otra parte, el unilateralismo emprendido por Estados Unidos sembró la desconfianza y la suspicacia entre los diferentes gobiernos, provocando un incremento de la militarización de las relaciones internacionales. En definitiva, los costes de la lucha antiterrorista sobrepasaban a los beneficios a simple vista. Entonces, ¿cómo explicar la decisión del gobierno de Estados Unidos de aplicar la lucha antiterrorista? Una posible explicación es la ineptitud de los gobernantes que no supieron prever las consecuencias que dicha decisión arrastraba. A continuación, vamos a intentar desarrollar otras posibles explicaciones que influyeron en su toma de decisiones.

A comienzos del siglo xxi, la promesa de que el proceso de globalización traería beneficios para todos se estaba derritiendo con el calor producido por la crisis económica. El fracaso del proceso de globalización a la hora de generar riqueza para todos y acabar con la pobreza persistente y la injusticia social se tradujo en una agitación global que se manifestaba de diferentes formas. En algunas partes se produjo un renacimiento del socialismo con la activación de movimientos y organizaciones contrarias al proceso de globalización. En algunos lugares, incluso llegaron al poder gobiernos contrarios al ordenamiento global. En otras partes, se exacerbaron conflictos nacionalistas y étnicos ya existentes. Y en otros lugares, emergió con fuerza el integrismo religioso como una respuesta al proceso de globalización.

Esta agitación creciente inquietó a los sectores más conservadores de la élite global, que siempre habían desconfiado de las estructuras multilaterales y de los mecanismos de dominación indirectos que habían promovido los liberales durante la década de 1990. Una vez que Estados Unidos fue el blanco de ataque directo por parte de rebeldes provenientes de la periferia, estos grupos conservadores tomaron partido por medidas urgentes de represión directa para mantener el orden global. Este es el verdadero origen de la "lucha antiterrorista". Buena parte de los aspectos recalcitrantes de las adversidades sociales, políticas y económicas que estaba experimentando el sistema fueron agrupados bajo el calificativo de "terrorista". El objetivo fundamental de la lucha antiterrorista era 
aplastar a los grupos violentos y no violentos, opuestos al proceso de globalización. En segundo lugar, se contemplaba la problemática de la creciente rebeldía de los Estados de la periferia. El propósito no era replantear los mecanismos estructurales del sistema internacional, sino simplemente proveerlos de una forma más poderosa de actuación bajo un nuevo modo de legitimación. ${ }^{74}$

La respuesta del sistema frente al desafío que representaba el fenómeno terrorista fue formar una nueva política de seguridad que reforzó los poderes de los gobiernos y desencadenar la lucha antiterrorista que legitimaba el uso de la fuerza para garantizar la expansión del proceso de globalización. El planteamiento de seguridad adoptado por Washington consistía en que Estados Unidos y sus aliados tenían el deber de construir, incluso a través de intervenciones militares, sistemas y gobiernos democráticos en los Estados de la periferia del sistema internacional. Algunos de esos Estados estaban atrasados económicamente y mantenían regímenes autoritarios contrarios al proceso de globalización, especialmente los países islámicos y los antiguos países comunistas. Estos factores los convertían en Estados inestables para el sistema global y en focos de resistencia al proceso de globalización. La sustitución de estos regímenes autocráticos por sistemas democráticos proporcionaría mayor estabilidad y seguridad al sistema internacional, y facilitaría la instauración de un orden normativo más sólido. ${ }^{75}$

Por tanto, la lucha antiterrorista de la administración Bush estableció una relación directa entre democracia y seguridad. A mayor democracia, mayor seguridad, por lo que, cuanto más se extendiera la democracia, más seguro sería el mundo. Se argumentaba que, dado que las democracias son los miembros más responsables del escenario internacional, promover este sistema de gobierno era la medida más efectiva a largo plazo para reforzar la estabilidad internacional, reducir los conflictos regionales y contrarrestar al terrorismo. De esta manera se podría extender la paz y la prosperidad. Esta concomitancia entre democracia y seguridad en la estrategia estadounidense puede explicarse por la

${ }^{74}$ Biel, op. cit., p. 517.

${ }^{75}$ Heazle e Islam, op. cit., p. 1. 
creciente omnipotencia del sector militar industrial en Estados Unidos $^{76}$ y por la necesidad de mantener el libre mercado y la democracia liberal como base de la hegemonía estadounidense a nivel global.

Desde este punto de vista, cabe entender la "guerra global contra el terror" como un intento de reproducir las circunstancias de la Guerra Fría, en la que Estados Unidos ejercía un claro papel de liderazgo entre sus aliados. Esto significaba que los gestores del centro del sistema ya no creían que fuera efectiva la vieja promesa del desarrollo y el abandono de la pobreza para mantener a las clases oprimidas bajo control, conque recurrían al militarismo para asegurar el orden. ${ }^{77} \mathrm{El}$ orden represivo debía compensar la debilidad de la persuasión. Los atentados del 11-S fueron un detonador tanto como un instrumento para activar esta nueva política. Su dimensión espectacular jugó un papel principal en la difusión de una sensación de vulnerabilidad que se extendió a todo el centro del sistema, pero principalmente a Estados Unidos. La instrumentalización de los atentados por parte de la administración de Bush sirvió para justificar su programa de políticas, que resultaron en un cambio de ruta en el proceso de globalización.

\section{LA EXPLICACIÓN CON TRASFONDO ECONÓMICO}

Detrás de la lucha antiterrorista había también motivaciones económicas. En el trasfondo de todas estas medidas de seguridad represivas en Estados Unidos había una situación económica complicada. La "crisis punto.com" (2000) había dejado al sistema económico en vías hacia la recesión. El gobierno de Bush culpaba de la mala situación económica a las políticas especulativas del presidente Clinton y su consecuencia final, el estallido de la burbuja tecnológica en el 2000. Como alternativa económica, el equipo de Bush proponía

\footnotetext{
${ }^{76} \mathrm{El}$ candidato a presidente G. W. Bush recibió 4.5 millones de dólares para su campaña del sector industrial armamentístico. Gandásegui y Castillo, op. cit., p. 376 .

${ }^{77}$ Biel, op. cit.
} 
colocar como locomotoras de la economía al sector energético y al sector militar.

La implementación de la lucha antiterrorista varió las necesidades del mercado y actuó como motor propulsor de algunos sectores. La demanda de artículos y servicios relacionados con la seguridad se incrementó enormemente. ${ }^{78}$ Las nuevas políticas de seguridad y las campañas militares requerían fuertes inversiones por parte del Estado, lo cual fomentaba una fuerte demanda de productos y servicios que las corporaciones del ramo se encargaban de suministrar. Este incremento del gasto público, por parte del Estado, reanimó los deprimidos mercados y se convirtió en una abundante fuente de contratos para el sector privado. ${ }^{79}$ La mayoría de estos contratos se acordaba con base en preferencias y no había licitación pública, con que se dejaban al descubierto los vínculos entre la industria armamentística y el gobierno. ${ }^{80}$

De esta manera, surgió un próspero mercado basado en la seguridad nacional. ${ }^{81}$ Muchas corporaciones redefinieron sus líneas de investigación y producción para adaptarse a las necesidades de este nuevo mercado, sobre todo las corporaciones dedicadas a las nuevas tecnologías y las comunicaciones, que habían hallado un filón con el desarrollo de modernos sistemas de vigilancia y

${ }^{78}$ El índice bursátil Spade Defense, la principal referencia para el mercado de la seguridad y la defensa, subió una media de 15\% entre los años 2001 y 2006, siete veces y media el incremento medio del índice, S\&P 500, que cubre las 500 principales corporaciones del mundo. Durand, Copinschi, Martin y Placidi Durand, op. cit.

${ }^{79}$ El Pentágono repartió 270000 millones de dólares al año entre contratistas privados durante el mandato de Bush, lo cual representa un incremento de 137000 millones de dólares desde su toma del poder. Las agencias de inteligencia otorgaron contratos por valor de 42000 millones de dólares al año, más del doble que en 1995. El Departamento de Seguridad Nacional entregó 130000 millones de dólares en contratos durante el periodo entre 11/09/01 y 11/09/06. Gandásegui y Castillo, op. cit., p. 376.

${ }^{80}$ De las más de setenta corporaciones estadounidenses implicadas en Afganistán e Iraq, $60 \%$ poseen empleados o miembros directivos que trabajan o mantienen importantes vínculos con funcionarios del gobierno, miembros del Congreso y militares de alto rango. Gandásegui y Castillo, op. cit., p. 376.

${ }^{81}$ Daniel Pereyra, Mercenarios: guerreros del imperio, Barcelona, El Viejo Topo, 2007. 
espionaje. Más de un tercio de la economía estadounidense pasó a depender directa o indirectamente de los contratos con el complejo militar. ${ }^{82}$ Esta tendencia suponía un arma de doble filo, ya que si bien los gastos en seguridad y defensa favorecían a ciertos sectores económicos, los gastos excesivos en este ámbito podrían perjudicar a la larga el crecimiento económico. Esto se debe al hecho de que cada vez más recursos se desvían hacia esta actividad y pueden hacer que la economía nacional pierda capacidad para responder a los desafíos comerciales en los sectores civiles. ${ }^{83}$

Con las nuevas políticas de seguridad, implementadas tras el 11-S, la industria del armamento se había encumbrado como una de las más lucrativas. Poderosas corporaciones controlaban este negocio en todo el mundo. De las diez principales corporaciones que se dedicaban a la producción de armamentos, o servicios relacionados con la defensa, siete tenían su sede en Estados Unidos. Por orden de ingresos estas corporaciones eran: Lockheed Martin, Boeing, Northrop Grumman, BAE Systems (Gran Bretaña), Raytheon, General Dynamics, EAds (UE), L-3 Communications, Thales (Francia) y Halliburton.

El mercado global de las armas convencionales ${ }^{84}$ es floreciente y no hay una verdadera voluntad de limitar el comercio internacional de armas. Muchos Estados transigen o colaboran con el tráfico de armas, obteniendo a cambio beneficio económico o ventajas políticas. Los límites para alcanzar un acuerdo son bien visibles. Los principales Estados exportadores de armas convencionales son los miembros del G-8 (a excepción de Japón). En especial, Estados Unidos destaca por encima de los demás. Durante el periodo 1995-1999, es decir antes de declarar la lucha antiterrorista, Estados Unidos ya controlaba el $50 \%$ del comercio mundial de

${ }^{82}$ Samir Amin, El capitalismo en la era de la Globalización, Barcelona, Paidós, 2000 , p. 67.

${ }^{83}$ Kennedy, op. cit., pp. 692-693.

${ }^{84}$ Se llama "armas convencionales" al armamento clásico para diferenciarlo de las armas de destrucción masiva. Este concepto agrupa el armamento pesado (carros de combate, artillería, misiles, aviones de combate, etc.) y el armamento ligero (pistolas, ametralladoras, minas, lanzagranadas, etc.). 
armas, seguido por Rusia con el 13\%, Francia con el 10\% y Gran Bretaña con el 6.5\%.

Por otro lado, proliferaron las corporaciones que prestaban servicios militares. Corporaciones, como Blackwater, movilizaban 20000 soldados mercenarios y poseían una flota aérea propia con bases militares por todo el mundo. Estas corporaciones militares, además de seguridad, también ofrecían logística, formación y servicios de información e inteligencia. Se calcula que la mitad del presupuesto del que disponen los servicios secretos estadounidenses, aproximadamente 20000 millones de dólares, se invierte en contratos con corporaciones militares. ${ }^{85}$ Los contratos del sector en 2005 alcanzaron unos 200000 millones de euros. ${ }^{86}$ Se calcula que las corporaciones del ramo ganaban unos 4000 millones de dólares al año sólo en Iraq, mientras que el presupuesto que manejó la onu para las misiones de paz entre 2006 y 2007 fue de 5250 millones de dólares. ${ }^{87}$

El recurso a mercenarios altamente profesionalizados es cada vez más frecuente. En Iraq han llegado a operar alrededor de 30000 efectivos contratados por las corporaciones, el gobierno de Estados Unidos y el iraquí. Lo mismo ocurre en Afganistán y en numerosos Estados de África, América y Asia. ${ }^{88} \mathrm{El}$ recurso a las tropas mercenarias cumple con varios objetivos. Para los Estados, se trata de suplir las carencias de las fuerzas armadas; de limitar el tributo en vidas de soldados regulares y el desprestigio que implicaría la acumulación de bajas de reclutas nacionales; o su empleo para operaciones de "guerra sucia". Las corporaciones también recurren a la contratación de mercenarios que les proporcionan defensa de sus instalaciones y personal en zonas de guerra, o para operativos de desestabilización interna en Estados donde tienen intereses.

La aparición de esta estructura militar paralela a la de los Estados pone en riego el monopolio de éstos sobre el uso de la fuerza. Muchos expertos del ramo pasan a trabajar para las corporaciones,

${ }^{85}$ Uesseler, op. cit., p. 31.

${ }^{86}$ Uesseler, op. cit., p. 38.

${ }^{87}$ Klein, op. cit.

${ }^{88}$ Se calcula que actúan en unos 160 Estados por todo el mundo. Uesseler, op. cit., p. 17. 
donde están mejor pagados. ${ }^{89}$ De hecho, la mayoría de sus empleados son antiguos militares y funcionarios. De la misma manera, la mayor parte de sus contratos provienen de los Estados. Aproximadamente, estas corporaciones emplean de manera directa a $1.5 \mathrm{mi}$ llones de personas por todo el mundo. ${ }^{90}$ La lealtad y legalidad de la actuación de estos soldados plantea múltiples interrogantes. A raíz de su carácter de empleados de estas grandes corporaciones, las convenciones y las leyes de proscripción e ilegalidad de mercenarios promulgadas por la onU se tornan irrelevantes.

\section{Conclusiones}

La lucha antiterrorista posee una lógica que obedece más al objetivo de reforzar la hegemonía de Estados Unidos a nivel global, que a garantizar la seguridad en el sistema internacional. En función de su papel de liderazgo, Washington se ha esforzado en exportar los valores democráticos a todo el mundo a través de los flujos comerciales y culturales del proceso de globalización; y cuando no ha sido posible ha recurrido al uso de la fuerza. Sin embargo, esta incesante obsesión de imponer la democracia por cualquier medio podría amenazar a la propia democracia. Estados Unidos, como potencia hegemónica, puede fomentar la democracia en el extranjero, siempre que se aplique de manera que respete la legalidad internacional y sea sensible con las aspiraciones y los derechos de otros Estados. De otra manera, la propia democracia se vería desacreditada por una retórica democrática vacía e hipócrita. Por tanto, los imperativos de la hegemonía no casan bien con los principios de la democracia. Hasta el punto de que la hegemonía puede poner en peligro la democracia que la sustenta.

Para más inri, el sistema democrático estadounidense ha sufrido un deterioro constante a lo largo de la Globalización. En parte, este deterioro se debe a las políticas de seguridad internas implementadas como respuesta a reacciones provocadas por el ejercicio

${ }^{89}$ Pereyra, op. cit.

${ }^{90}$ Uesseler, op. cit., p. 38. 
de su hegemonía global. Por tanto, el propio ejercicio de la hegemonía global ha erosionado la democracia a nivel interno en Estados Unidos. A nivel externo, el discurso de Washington a favor de la democracia y la seguridad elevó expectativas en buena parte de la sociedad internacional, que en la práctica se ha sentido frustrada cuando se enfrenta a la realidad de un ordenamiento global con un importante déficit democrático. La constelación de oIG promocionada por Washington está muy lejos de representar un ejemplo de funcionamiento multilateral y democrático, y básicamente es una fachada que asegura los intereses de Estados Unidos y sus aliados. Ambos vectores, el que representa el debilitamiento de la democracia a nivel interno en Estados Unidos y el que representa la frustración de la sociedad internacional al constatar la inexistencia de un ordenamiento global con un funcionamiento democrático, convergen provocando una fuerte tensión en el sistema internacional que debilita la legitimidad del ordenamiento global.

Por tanto, podemos concluir que, si el objetivo de la política de seguridad del gobierno Bush tras los atentados del 11 de septiembre era restablecer el orden, fue un sonoro fracaso. Este fracaso de la política de seguridad global posterior al 11-S deja claro que el gobierno de Bush no tomó las decisiones correctas. Sin embargo, todavía no queda claro si el gobierno de Bush cometió un error al no calcular apropiadamente las consecuencias de su decisión o si tomó dicha decisión de manera consciente, a pesar de haber calculado sus consecuencias. El esclarecimiento de este punto se dejará para investigaciones futuras.

\section{Bibliografía}

Abele, Robert P., A User's Guide to the USA Patriot Act and Beyond, Lanham, University Press of America, 2005.

Agamben, Giorgio, Estado de Excepción, Madrid, Pre-textos, 2003.

Amin, Samir, El capitalismo en la era de la Globalización, Barcelona, Paidós, 2000.

Arrighi, Giovanni, Adam Smith en Pekin, Madrid, Akal, 2007. 
Aydinli, Ersel y James N. Rosenau, Globalization, Security, and the Nation State, Albany, SUNY Press, 2012.

Azcárate, Blanca y Ferrán Montesa (eds.), El Atlas de las mundializaciones, Valencia, Mondiplo, 2011.

Bartholomew, Amy (ed.), Empire's Law, Londres, Pluto, 2006.

Baylis, John y Steven Smith, The Globalization of World Politics, Nueva York, Oxford University Press, 2005.

Biel, Robert, El nuevo imperialismo, México, Siglo XXI, 2007.

Booth, Ken y Timothy Dunne (ed.), Worlds in collision, Nueva York, Palgrave Macmillan, 2002.

British Antiterrorist Act, http:/ / www.legislation.gov.uk/ukpga/2001/24/ contents

Brzezinski, Zbigniew, El dilema de EEUU: ¿Dominación global o liderazgo global?, Barcelona, Paidós, 2005.

Buchanan, Allen y Robert O. Keohane, "The Preventive Use of Force: A Cosmopolitan Institutional Proposal", Ethics $\mathcal{E}$ International Affairs, vol. 18, núm. 1, 2004, pp. 1-22, http:/ / onlinelibrary.wiley.com/doi/10. 1111/j.1747-7093.2004.tb00447.x/full

Bulard, Martine, Alain Gresh, Philippe Rekacewicz, Catherine Samary y Olivier Zajec (eds.), El Atlas de las nuevas potencias emergentes, Valencia, Cybermonde, 2012.

Buzan, Barry et al., Security: A New Framework for Analysis, Boulder, Lynne Rienner Publishers, 1998.

Buzan, Barry y Eric Herring, The Arms Dynamic in World Politics, Boulder, Lynne Rienner, 1998.

Buzan, Barry y Ole Waever, Regions and Powers: The Structure of International Security, Cambridge, Cambridge University Press, 2003.

Chomsky, Noam, Estados fallidos, Barcelona, Público, 2010.

Durand, Marie-Françoise, Philippe Copinschi, Benoît Martin y Delphine Placidi (eds.), Atlas de la globalización: comprender el espacio mundial contemporáneo, Valencia, Universitat de Valencia, 2008.

Falk, Richard, La globalización depredadora: una crítica, Madrid, Siglo XXI España, 2002.

Fernández, Yolanda, China. La construcción de un Estado moderno, Madrid, Catarata, 2001.

Gandásegui, Marco A. y Dídimo Castillo (coord.), Estados Unidos: la crisis sistémica y las nuevas condiciones de legitimación, México, Siglo XXI, 2010. 
Heazle, Michael e Iyanatul Islam, Beyond the Iraq war, Northampton, Edward Elgar, 2006.

Hinojosa, Luis M., La financiación del terrorismo y las Naciones Unidas, Madrid, Tecnos, 2008.

Kaldor, Mary, El poder y la fuerza, Barcelona, Tusquets, 2010.

Kennedy, Paul, Auge y caída de las grandes potencias, Barcelona, Random House, 2011.

Klein, Naomi, La doctrina del shock, Barcelona, Paidós, 2010.

Merlos, Alfonso, Terror.com, Universidad de Navarra, 2008.

Naciones Unidas, Anuario de las Naciones Unidas sobre desarme, United Nations Publications, vol. 29, 2004.

Naciones Unidas, "Deber de protección", http://www.un.org/es/preventgenocide/adviser/responsibility.shtml

Nye, Joseph S., La paradoja del poder norteamericano, Madrid, Santillana, 2003.

Palomo, Aleksandro, "Apuntes teóricos para el estudio de la Globalización desde la perspectiva de las Relaciones Internacionales", en $\mathrm{CON}$ fines de Relaciones Internacionales y Ciencia Política, vol. 8, núm. 16, Tecnológico de Monterrey, 2012.

Patriot Act, http://www.justice.gov/archive/ll/highlights.htm

Plan de Estrategia de Seguridad Nacional de los Estados Unidos, http:/ / www.usembassy-mexico.gov/bbf/ej/EJ\% 201202sp_estrategia.pdf

Pereyra, Daniel, Mercenarios: guerreros del imperio, Barcelona, El Viejo Topo, 2007.

Poch, Rafael, La actualidad de China, Barcelona, Crítica, 2009.

SIPRI, Yearbook 2009: Armaments, Disarmament and International Security, Nueva York, Oxford University, 2009.

—, Yearbook 2005. Armaments, Disarmament and International Security. Oxford University. 2005.

Todd, Paul y Jonathan Bloch, Global Intelligence, Nueva York, Zed Books, 2004.

Toussaint, Eric, La bolsa o la vida. Las finanzas contra los pueblos, San Sebastián, Edt. Tercera prensa-Hirugarren prensa, 2002.

Uesseler, Rolf, La guerra como negocio, Barcelona, Belacqua, 2007.

Wallerstein, Immanuel, Capitalismo histórico y movimientos antisistémicos, Madrid, Akal, 2004.

Westra, Laura, Faces of State Terrorism, Leiden, Brill, 2012. 